\title{
PARALISIA CEREBRAL: CONHECIMENTO DAS MÃES SOBRE O DIAGNÓSTICO E O IMPACTO DESTE NA DINÂMICA FAMILIAR ${ }^{1}$
}

\author{
Eucia Beatriz Lopes Petean ${ }^{2}$ \\ Marília Ferreira Murata
}

\begin{abstract}
RESUMO: A Paralisia Cerebral (P.C.) é um problema neurológico, que envolve danos da função neuromuscular, com ou sem déficit intelectual. Os danos são de caráter não progressivo e se devem a lesões cerebrais ocorridas no período pré-natal, peri e pós-natal. As conseqüências são alterações motoras e/ou psíquicas, paralisias, epilepsia, hipotonia, entre outros. Os problemas da criança com P.C. podem ocasionar transtornos aos pais. $O$ objetivo deste trabalho consiste em apreender qual o conhecimento que as mães possuem sobre P.C. e o impacto desta sobre a dinâmica familiar. Foram realizadas 20 entrevistás com mães de crianças com diagnóstico de P.C., de recém nascidos a 4 anos, atendidas no Ambulatório N P H C da FMRP-USP, no Setor de Estimulação Precose da APAE-RP, no Centro de Educação E P. Foi utilizado um roteiro semi-estruturado, previamente testado. Os dados obtidos passaram, pela Análise Temática de Conteúdo. As limitações percebidas são principalmente atrasos geral e atraso motor. O impacto da deficiência na família, positivo ou negativo altera a dinâmica familiar, e a mãe é a principal afetada.
\end{abstract}

Palavras-chave: Paralisia Cerebral, Família, Deficiência

\section{CEREBRAL PHAUSY: MOTHER KNOWLEDGE ABOUT THE DIAGNOSIS AND THE MEANING OF THIS IN THE FAMILY DYNAMIC}

\begin{abstract}
A Cerebral Phausy (CP) is a neurological problem that involves damages in neuromuscular function, with or without intellectual deficit. The damages don't have a progressive character and occur after a cerebral lesion that happens in the pre, near or post natal period. It may have consequences like motor or psychological alterations, paralysis, epilepsy, among others. Children with CP may cause several disruptions to parents. The objective of this research was to find out the knowledge the mothers have about $\mathrm{CP}$ and its impact on family dynamic. 20 mothers with a CP new born or 4 years child, from three different intitutions, were interviewed. It was used a semi-structured guide, previously tested. The obtained data were analyzed, based on the Thematic Analysis of Contents. The knowing limitations were about general and motor delay. The influence of the handicap on the family is positive or negative, but there are changes on family dynamics, and the mother is the main affected member.
\end{abstract}

Key words: Brain Paralysis, Family, Deficiency

A Paralisia Cerebral (P.C.) é um dos mais importantes e freqüentes problemas neurológicos, acarretando deficiências físicas e/ou mentais. Apesar de os critérios de definição não serem perfeitamente claros, nem mesmo concordantes, estima-se que devam existir cerca de seis casos a cada mil crianças nascidas vivas.

Devido à multifatoriedade causal, a Parali-

\footnotetext{
${ }^{1}$ Artigo recebido para publicação em 03/01; aceito em 07/01

${ }^{2}$ Endereço para correspondência; Eucia Beatriz Lopes Petean, Departamento Psicologia e Educação, Faculdade de Filosofia, Ciências e Letras de Ribeirăo Preto, USP, Av. Bandeirantes, 3900, Monte Alegre, Cep. 14040-901, e-mail ebpetean @ffclrp.usp.br
}

sia Cerebral tem sido definida diferentemente por vários autores. Assim Machado, Fagundes e Assis (1987), Nery (1983) e Brandão (1992) definem a P.C. como distúrbio de função motora devido a lesões cerebrais ocorridos no sistema nervoso central no período de desenvolvimento.

Alguns autores como Yamamoto, Koeda, Ishii e Takeshita (1999) consideram a Paralisia Cerebral como uma síndrome que causa múltiplos danos ao cérebro.

De acordo com Figueiredo (1983) a Neurologia Pediátrica define a P.C. como um conjunto de

Paidéia, FFCLRP-USP, Rib. Preto, ago/dez/2000. 
afecções encefálicas da primeira infância, devida a causas diversas e tendo como substrato anatômico anomalias de desenvolvimento do encéfalo (malformações congênitas ou lesões encefálicas destrutivas); e estas, constituindo-se em lesões estáticas, não progressivas, que ocorrem no período prénatal, durante o parto ou na primeira infância, e incluem alterações no desenvolvimento, lesões destrutivas e infecções encefálicas. $O$ distúrbio funcional do paralítico cerebral vai se estruturando com o passar do tempo e manifestando-se através de uma semiologia evolutiva, porém, a condição não é progressiva.

A partir dessas definições pode se dizer que a Paralisia Cerebral decorre de lesões cerebrais, que podem causar déficits neuromotores e/ou mentais. Essas lesões acontecem no período pré-natal, peri-natal ou na primeira infância, ou seja, durante o periodo de desenvolvimento do encéfalo sendo de etiologia multifatorial.

Machado e cols (1987) apresentam os seguintes fatores como possiveis causas de P.C.; prénatais (infecções uterinas, transtornos no metabolismo materno), perinatais (anoxia, parto prolongado ou prematuro); ou pós-natais (acidentes vasculares, convulsão, intoxicações, entre outros).

Estudos recentes apontam alguns outros fatores de risco para Paralisia Cerebral. Burguet e cols (1999) ressaltam como eventos pré-natais altamente sugestivos que se constituem como fatores de risco para P.C. a ruptura prematura de membranas e a gravidez de gêmeos com placenta única. Destacam, também, a síndrome de angústia respiratória como fator pós-natal de risco.

Arpino, Curatolo, Stazi, Pellegrini e Vlahov (1999) consideram que tipos genéticos diferentes e intenso jogo de exposições ambientais podem acarretar manifestações de Paralisia Cerebral combinada com retardamento mental, epilepsia, ou somente $\mathrm{Pa}$ ralisia Cerebral.

Em função deste quadro, os portadores de Paralisia Cerebral podem apresentar deficiências múltiplas, resultantes, de associação com deficiência mental, auditiva ou visual; podem ter problemas expressivos na área psicomotora, outros específicos de aprendizagem ou emocionais, movimentação descoordenada bem como dificuldade de fala. Ainda podem apresentar alterações psicológicas, psiquiá-

Paidéia, FFCLRP-USP, Rib. Preto, ago/dez/2000. tricas, de comunicação (decorrentes de suas dificuldades musculares) ou dificuldades sociais. No entanto, estas últimas, muitas vezes, advém de fatores ligados às reações sociais e familiares em relação à deficiência física da criança.

Os trabalhos de Petean (1995) e Brunhara e Petean (1999) têm salientado o impacto do nascimento de um bebê com problemas, o que, de acordo com Mac Collum (1984) implica em uma nova realidade para a família.

O impacto é tão grande que compromete o estabelecimento de vínculo, a aceitação do filho a compreensão das informações, e perceber-se-á alteração na rotina diária, nos sonhos e projetos de cada membro da família, que se desestrutura sendo necessário longo processo para que retome o equilíbrio.

Neste sentido a informação, o modo e o momento em que é transmitida, e o seu conteúdo são fundamentais neste processo.

É de suma importância a compreensão que os pais apresentam sobre as causas do problema e principalmente sobre as conseqüências advindas dele.

Expectativas positivas ou negativas quanto ao desenvolvimento e futuro do filho podem ser influenciados pelo entendimento das informações passadas, prejudicando em algum momento, o oferecimento dos recursos especializados necessários ao bom desenvolvimento da criança.

Assim Brunhara e Petean (1999) salientam a necessidade de que as informações sejam dadas por profissionais experientes, em linguagem simples e acessível, que possibilite a compreensão adequada do que está sendo falado.

Regen, Ardore e Hoffmann (1993), Petean (1995) e Petean e Pina Neto (1998) enfatizam a necessidade de que a família receba o maior número possível de informaçōes, que as dúvidas sejam esclarecidas para que possam assim decidir com segurança as condutas fundamentais ao bom desenvolvimento do filho.

A aceitação do bebê e o processo de reestruturação da família dependem, em grande parte, do como os pais entendem o diagnóstico, atribuíndo a ele um significado para suas vidas e de seu filho.

O presente trabalho tem por objetivo conhecer quais informações as mães possuem sobre Paralisia Cerebral e qual a consequâência deste diagnóstico na estrutura familiar 


\section{Método}

\section{Participantes}

Foram entrevistadas 20 mães de crianças que apresentam o diagnóstico de Paralisia Cerebral e que são atendidas no Serviço de Neurologia Infantil do HC da FMRP-USP, no setor de Estimulação Precose da APAE ou no Centro de Educação Especial Egydio Pedreschi, ambos da cidade de Ribeirão Preto. As participantes foram contatadas nos serviços em que eram atendidas, quando se explicavam os objetivos da pesquisa e solicitava-se sua participação. Havendo concordância marcava-se data, local e hora para realização das entrevistas e solicitava-se que assinassem o Termo de Consentimento Livre Esclarecido.

\section{Procedimento de Coleta de Dados}

Visando o objetivo da pesquisa, de verificar o conhecimento que as mães possuem sobre o problema de seu filho, dados estes que são de domínio do sujeito e que só ele é capaz de informar (Cannel \& Kahn, 1974), optou-se pela realização de entrevistas semi estruturadas utilizando um roteiro com temas direcionados às questões do projeto.

O roteiro foi composto pelos seguintes temas: Causas e Extensão da deficiência, Reação dos Pais ao saberem da notícia e quem os informou, conhecimento geral sobre Paralisia Cerebral, $\mathrm{O}$ que os pais pensam sobre os filhos, Como é o relacionamento deles com a criança, Expectativas sobre o futuro que deram origem a um número variado de questões. Nesse presente trabalho apresentamos os dados referentes à identificação da mãe e da criança, conhecimento sobre a problemática do filho, desenvolvimento atual da criança, e impacto da deficiência na dinâmica familiar.

\section{Análise dos Dados}

Optou-se por realizar análise qualitativa uma vez que sua função é apreender o caráter multidimensional dos fenômenos em sua manifestação natural e captar os diversos significados de experiências vividas auxiliando a compreensão do individuo no seu contexto (Biasoli-Alves, 1998).

De acordo com Minayo (1993) "fazer uma análise temática consiste em descobrir os núcleos de sentido que compõem uma comunicação cuja presença ou freqüência signifique alguma coisa para o objetivo analítico visado".

Atendo às recomendações da literatura, para iniciar a análise temática de conteúdo, realizou-se inicialmente uma leitura exaustiva do material das entrevistas. Em um segundo momento elaboraramse os recortes, determinando assim os temas que norteariam a análise.

Em função do tipo de análise proposta, todas as categorias referentes a um tema são apresentadas, não havendo preocupação em quantificação.

As mães foram identificadas atribuindo-se, aleatoriamente, a elas números de 01 a 20 .

\section{Caracterização dos Participantes}

Participaram deste estudo 20 mães de crianças com o diagnóstico de Paralisia Cerebral. A idade das mães ao engravidarem variou de 15 a 36 anos sendo que $45 \%$ tinha até 20 anos. $45 \%$ apresentou nível de escolaridade de $1^{\circ}$ grau incompleto.

Em relação às crianças, 14 são do sexo masculino (a maior parte), 45\% são segundo ou terceiro filho do casal.

Em relação a causa da paralisia cerebral, 07 tiveram anoxia neonatal, 07 apresentavam anoxia associada a uma síndrome e os demais apresentavam fatores tais como, meningite, toxoplasmose e mitocardiopatia

\section{Resultados e Discussão}

Os relatos das mães durante as entrevistas, permitiram apreender o conhecimento que estas possuem sobre o diagnóstico, o desenvolvimento do filho e as consequiências na dinâmica familiar.

\section{1) Conhecimento da Mãe Sobre Paralisia Cere- bral}

\author{
Sabem Nome \\ "Falou que tinha dado Paralisia Cerebral \\ nele" (Mãe 15) \\ "Acho que a gente sabe, assim né, paralisia \\ cerebral..." (Mãe 18) \\ - Sabem Causas \\ "Não é uma doença, é uma conseqüência da \\ anóxia, entendeu?” (Mãe 14)
}

Paidéia, FFCLRP-USP, Rib. Preto, ago/dez/2000. 
"Ela falou é por causa da falta de ar no cérebro" (Mãe 15)

\section{- Sabem Conseqüências}

"Mais ou menos. Eu não sei muito bem não (...) Eu acho assim, né que é, paralisia parte do corpo, sei lá. Não ainda, não conversa. Eu acho que é isso". (Mãe 10)

"Acho que, é o cérebro não está comandando corretamente o corpo como devia. Foi um, uma, como se fosse uma regressão, não é?"

(Mãe 18)

"A criança não anda, não fala. Tem criança que näo anda, tem criança que não fala, né, fica com problema"

(Mãe 19)

\section{- Não Sabem}

"Eles informaram o que tem acontecido $e$ como eu devo proceder com..., tratando ele, fazendo, ensinando ele andar" (Mãe 02)

$$
\text { “...eu não sei” (Mãe 12) }
$$

O Conhecimento demonstrado pelas mães sobre o diagnósticoé simplificado. Ora citam o nome, ora citam a causa ou conseqüências sem no entanto estabelecerem relação entre eles.

Diferentes estudos (Brandão, 1992; Leitão, 1983; Puyuelo, 1992; e Yamamoto, \& cols 1999) têm apontado para as divergências conceituais e complexidade dos fatores causais da Paralisia Cerebral, e que muitas vezes dificulta o diagnóstico médico.

É provável que isto esteja refletido no relato das mães, uma vez que a complexidade das informações dificulta a compreensão e a apreensão.

\section{2) Desenvolvimento da Criança}

\section{- Atraso Geral}

"O médico disse que ele tem atraso, né?" (Mãe 10)

"Ela vai atrasar um pouco pra aprender as

Paidéia, FFCLRP-USP, Rib. Preto, ago/dez/2000. coisas (...) O que eu sei é que ela vai atrasar um pouco pra desenvolver. E tá atrasando mesmo. Porque ela tá na fase de nenê agora"

(Mãe 12)

“... que se eu fizesse fisioterapia, ele ia fazer tudo normal, com o tempo, mas tudo mais tarde, sabe? Gatinhar, falar, tudo mais tarde, mas que ele ia ser uma criança como outra qualquer"

(Mãe 18)

\section{- Atraso Motor Global}

"Ele é bem hipotônico. Ele senta no colo, mas mesmo assim, ele não afirma o tronco (...) Agora que ele tá começando a segurar, mas a cabecinha..."

(Avó 08)

"Ele não anda, nem não senta, ainda. Ele não afirma" (Mãe 10)

"Ela é molinha, né? Ela é um pouquinho mole no tronco. Não tem muita firmeza. Ela cai para trás. Ela cai para o lado. Cai para a frente".

(Mãe 19)

\section{- Atraso na Linguagem \\ "Ela não fala (...) Ela emite som"}

(Mãe 04)

"Não, não fala nada"

(Mãe 05)

\section{- Progresso no Desenvolvimento}

"Levanta. Às vezes ela quer alguma coisa que tá no alto, ela vai, levanta e pega (...) Ela gatinha" (Mãe 01)

"Ele sobe nos lugares, ele desde. Com o andador ele também faz de tudo (...) Ele se arrasta (...) Mas, ele tá indo bem, já... caminha direitinho, já. Não gosta muito, mas vai"

(Mãe 02)

"Ah! Ele tá melhorando 100\% do que ele era, né? Ele era bem mais durinho. Agora ele já gatinha. Senta. Come sozinho (...) Sabe pedir as coisas, quando quer também (...) Fala. (...) Ele fica em pé tam- 
bém, assim, segurando no carrinho, ele fica em pezinho sozinho" (Mãe 06)

A partir dos relatos das mães, verifica-se que essas crianças apresentam atrasos e deficiências motoras, que em sua maioria, são severos, incluindo o geral, o motor global, e na linguagem.

Se considerarmos as características e conseqüências da Paralisia Cerebral descritas pelos autores, Cardoso (1971); Dubowitz (1973); Figueiredo (1983); Alvarenga (1983); Machado \& cols (1987); Brandão (1992); Puyelo (1992), poderemos considerar os atrasos relatados pelas mães, como esperados para o diagnóstico que apresentam, demonstrando assim, que elas possuem conhecimento adequado sobre as limitações de seus filhos.

Entretanto é importante salientarmos a preocupação de algumas mães em relatar os progressos apresentados por seus filhos, demonstrando o quanto estão acompanhando o desenvolvimento deste $\mathrm{e}$ quão significativos são as pequenas mudanças, sem no entanto implicarem em negação do diagnóstico.

\section{3) Impacto da Deficiência na Dinâmica Familiar}

\section{- $\underline{\text { Mudou }}$}

"Ah! Mudou muito. Porque eu saia e não saio mais. Trabalhava e agora não trabalho mais. Agora eu só fico pra ela, né? Fico em casa só pra cuidar dela"

(Mãe 01)

"Muda tudo. Mudou tudo. Mudou tudo assim... Eu pensava assim em trabalhar, né? Eu Não vim pra ficar (...) Eu vim pra trabalhar, né? Pra melhorar. Chegou aqui (...) Eu não tenho tempo pra sair à tarde. Eu não saio pra lugar nenhum, a não ser hospital, lá na UNAERP e na APAE. Eu não vou em lugar nenhum. Não conheço nada"

(Mãe 05)

"Ah! Mudou, Vichi! (...) Foi bem melhor, né? Nossa Senhora! Não tem nada melhor do que um fio, né?

(Mãe 10)

"Ah! Mudou, né? Não tem jeito de não mudar, muda, né? Eu acho assim que a minha vida é mais para ela, só para ela, ando mais, a gente fica, a gente começa a ficar mais humilde, né?"

(Mãe 19)

\section{Não mudou}

"A mesma coisa. Os mesmos planos" (Mãe 03)

"Não. Eu realizei todos. Eu queria ter a minha casa. Eu queria ter o quartinho dela. E eu realizei todos. A deficiência dela, não me impediu nada" (Mãe 04)

"Não. Tudo continua do mesmo jeito. (...) Ficou tudo normal (...) Não mudou nada (...) Todo plano pra mim continuou ali. Do mesmo jeito.

(Mãe 12)

Quando se fala do impacto causado pela deficiência da criança sobre a dinâmica familiar, este apresenta-se diversificado. Algumas mães consideram que a vida familiar não foi afetada, e que seus planos para a criança não mudaram depois que soube da deficiência do filho. Entretanto, há quem considere que a vida se modificou, pois teve que abdicar do tempo antes dedicado a si, a fim de cuidar do filho. Outras consideram que as modificações foram positivas, pois, devido às dificuldades, aprenderam uma nova maneira de ver o mundo, e que as mudanças acarretaram mais união na família e carinho entre os membros.

Neste sentido Irvin et al (1992) afirmam que o nascimento de um bebê portador de deficiência pode unir os seus pais, quando existe mútuo apoio e comunicação para que ocorra a adaptação, porém também pode separá-los quando não compartilham as responsabilidades.

Em relação às modificações na dinâmica familiar apontadas pelas mães, Mckeever (1992) salienta que, os cuidados com a criança portadora de deficiência fica sobre o encargo da mulher, devido às expectativas culturais sobre gênero, relações familiares, trabalho doméstico e criação de crianças. Essa experiência é estressante para elas, afetando quase todos os aspectos de suas relações, muitas vezes levando-as ao isolamento.

Fica evidente pelos relatos que a presença da criança por si só modifica a dinâmica familiar, 
sendo que o tipo de modificação provocada (positiva ou negativa) e a intensidade da mesma, depende de cada família, da gravidade da deficiência e do significado que esta tem para cada família.

\section{Considerações Finais}

Os dados aqui apresentados deixam claro a dificuldade que as mães têm em informar sobre o diagnóstico da Paralisia Cerebral. Entretanto as consequiências desta sobre o desenvolvimento por serem evidentes são facilmente percebidas, o que de certa forma facilita a compreensão da necessidade de atendimentos especializados para seus filhos.

O impacto da deficiência na família é fato indiscutível, altera a dinâmica familiar, diferentemente para cada um dos seus membros provocando reestruturação em suas vidas.

Em função dos relatos apresentados consideramos importante que os profissionais esclareçam os pais sobre o diagnóstico da Paralisia Cerebral enfatizando principalmente a relação entre o nome do diagnóstico e as consequiências apresentadas por ele.

Há necessidade de acompanhamento psicológico dos pais, para que reestruturem suas vidas de forma que a deficiência do filho não possa ser considerada como o único fator causal para que a família abdique de seus sonhos e planos.

\section{Referências Bibliográficas}

Alvarenga, H. (1983). Diagnóstico diferencial da Paralisia Cerebral. Em: A. Leitão (Org.), Paralisia Cerebral diagnóstico, terapia reabilitação (pp. 31-36). Rio de Janeiro Livraria Atheneu.

Arpino, C., Curatolo, P., Stazi, M.A., Pellegrini, A. \& Vlahov, D. (1999). Differing risk factors for Cerebral Palsy in the presence of mental retardation and epilepsy. Itália Journal of Child Neurology, 14(3) pp 151-155.

Biasoli-Alves, Z.M.M. (1998). A pesquisa em psicologia - análise de métodos e estratégias na construção de um conhecimento que se pretende científico. Em: G. Romanelli. \& Z.M.M. BiasoliAlves (Orgs.), Diálogos Metodológicos Sobre Prática em Pesquisa (pp. 135-157). Ribeirão Preto: Legis Summa.

Brandão, J.S. (1992). Bases do tratamento por Paidéia, FFCLRP-USP, Rib. Preto, ago/dez/2000. estimulação precose de Paralisia Cerebral ou Dismotria Cerebral Ontogênica. São Paulo: Mennon.

Brunhara, F.C.R. \& Petean, E.B.L. (1998). Mães e filhos especiais: reações, sentimentos e explicações à deficiência da criança. Cadernos de psicologia e Educação - Paidéia, 9(16), 31-40.

Burguet, A., Monnet, E., Pauchard, J.Y., Roth, Ph., Fromentin, C., Dalphin, M.L., Allemand, H., Maillet, R. \& Menget, A. (1999). Some risk factors for Cerebral Palsy in very premature infants: importance of premature rupture of membranes and monochorionic twin placentation. Biology of the Neonate, 75, 177186.

Cannell \& Kahn (1974). Coleta de Dados por entrevista. Em: L.Festinguer \& D. A. Katz (Orgs.), $A$ pesquisa na Psicologia Social. Rio de Janeiro: E.F.G.V.

Cardoso, P.R. (1971). Fisioterapia na Paralisia Cerebral. São Paulo: Sarvier e Editora da Universidade de São Paulo.

Dubowitz, V. (1973). El nino hipotónico. Barcelona: Editorial Pediátrica.

Figueiredo, H.B. de (1983). Diagnóstico Precose da Paralisia Cerebral. Em: A. Leitão (Org.), Paralisia Cerebral: diagnóstico, terapia, reabilitação (pp. 15-30). Rio de Janeiro: Atheneu.

Irvin, N.A., Kennell, J.H. \& Klaus, M.H. (1992). Atendimento aos pais de um bebê com malformação congênita Em: M.H. Klaus \& J.H. Kennell (Orgs.), Pais/bebê: a formação do apego (pp. 245-275). Trad. Daise Batista, Porto Alegre: Artes Médicas.

Leitão, A. (1983). Incidência da paralisia cerebral. Em: A. Leitão (Org.), Paralisia Cerebral: diagnóstico, terapia, reabilitação (pp.7-12). Rio de Janeiro: Livraria Atheneu.

Machado, M.C.R., Fagundes, V.A. \& Assis, W. (1987). A educação do deficiente físico. São Paulo: Coordenadoria de Estudos e Normas Pedagógicas Secretaria de Estado da Educação, SE/ CENP.

McCollum, A.T. (1984). Gireving Over The Lost 
Dream-Excepcional Parent 14:9-12.

Mckeever, P. (1992). Mothering children who have severe choronic illnesses. Em: A.M. Ambert (Org.), The effect of children on parents ( $\mathrm{pp} .170-$ 190).

Minayo, M.C.S. (1993). O desafio do conhecimento: pesquisa qualitativa em saúde. São Paulo Rio de Janeiro: Hucitec - Abrasco.

Nery, O. (1983). Conceito classificação e incidência. In: A. Leitão (Org.), Paralisia Cerebral: diagnóstico, terapia, reabilitação (pp. 3-6). Rio de Janeiro: Atheneu.

Petean, E.B.L. (1995). Avaliação qualitativa dos aspectos psicológicos do aconselhamento genético através do estudo prospectivo do atendimento das famílias. Tese de doutorado, Universidade de Campinas.

Petean, E.B.L. \& Pina-Neto, J.M. (1998). Investigação em Aconselhamento Genético: Impacto de primeira notícia-reação dos pais a deficiência. Medicina, 31, 288-295

Puyuelo, M. (1992). Fonoaudiologia e Paralisia Cerebral infantil. Em: J.P. Casanova \& col. (Orgs.), Manual de fonoaudiologia (pp. 273-291) $2^{\mathrm{a}}$ ed. Porto Alegre: Artes Médicas).

Regen, M., Ardore, M. \& Hoffmann, V.M.B. (1993). Mães e filhos especiais: relato de experiência com grupos de mães de crianças com deficiência. Coordenadoria Nacional para a integração da Pessoa Portadora de Deficiência - CORDE.

Yamamoto, T., Koeda, T., Ishii, S. \& Takeshita, K. (1999). A patient with cerebral palsy whose mother had a traffic accident during pregnancy a difuse exonal injury. Brain \& Development, 21 , 334-336. 